\title{
Proyectando sobre el pasado industrial. La experiencia del taller de intervención sostenible en el patrimonio cultural
}

\author{
doi: 10.33264/rpa.201802-08 \\ Luis Rolando Rojas Morales \\ Escuela de Arquitectura UNIACC \\ Facultad de Arquitectura, Diseño y Artes Visuales UNIACC
}

\section{Resumen}

El presente artículo resume los principales aspectos del Taller de Intervención sostenible del patrimonio cultural, curso desarrollado en la Universidad UNIACC, ciudad de Santiago de Chile, desde el año 2016. Su relevancia consiste en por un lado, en contribuir al logro de los estándares de contenido definidos en los acuerdos internacionales sobre la enseñanza de la arquitectura como la Carta UNESCO / UIA de la formación en arquitectura, y por otro, plantear en la formación académica de pregrado, el desafío de pensar la producción de nuevos espacios en relación a edificios existentes con y sin patrimonialización, los cuales poseen valores patrimoniales que los convierten en parte importante de la historia de la ciudad y sus barrios.

Palabras clave: docencia, arquitectura, sostenibilidad, UNIACC, patrimonio industrial.

\begin{abstract}
This article summarizes the main aspects of the Workshop on Sustainable Intervention of Cultural Heritage, which is a course developed at UNIACC University, in Santiago de Chile, since 2016. Its relevance consists, on the one hand, of contributing to the achievement of the content standards defined in international agreements on the teaching of architecture, such as the UNESCO / UIA Charter of architecture training. On the other hand, of thinking about the production of new spaces in relation to existing buildings with and without patrimony character, through the academic formation of undergraduate students, based upon the heritage values that make them an important part of the history of the city and its neighborhoods.
\end{abstract}

Keywords: teaching, architecture, sustainability, UNIACC, industrial heritage. 


\section{Introducción}

En los últimos años, ha crecido en nuestra sociedad el interés por proteger y poner en valor un tipo de patrimonio urbano de carácter no monumental, cotidiano y barrial. Esta tendencia en Santiago de Chile se manifiesta en las iniciativas ciudadanas de patrimonialización de barrios como Matta-sur, Yungay, Suárez Mujica, San Eugenio, Matta-Viel y Huemul, en muchos de los cuales se hacen presentes hitos arquitectónicos como edificios y conjuntos representativos del pasado industrial y obrero de la ciudad de Santiago. El interés social en la protección y correcto uso del patrimonio cultural, ha motivado en el sector público acciones para responder a estos nuevos desafíos; destacan la patrimonialización nacional y local, la creación de unidades de patrimonio al interior de los municipios y la generación de concursos de arquitectura para la realización de obras públicas asociadas a inmuebles históricos relevantes.

Los concursos de arquitectura han sido una instancia mediante la cual empresas privadas y organismos del sector público exploran alternativas para el diseño y concreción de nuevos proyectos, más aún, cuando las obras se desarrollarán asociadas a una preexistencia arquitectónica patrimonial dando cuenta de la complejidad presente en el uso y reutilización del patrimonio cultural mediante nuevos proyectos de arquitectura. Ejemplo de esto, son los concursos Centro Cultural Estación Mapocho, edificio anexo Museo Histórico Nacional, Centro Cultural Gabriela Mistral, ex Cárcel de Valparaíso, ex Cárcel de Punta Arenas, Palacio Pereira, Reconversión de la ex Refinería San Ignacio, Paseo del Mar en Valparaíso, ex Sombrerería Girardi, Museo Ruinas de Huanchaca y posterior Plan Maestro Parque Cultural en el mismo sitio.

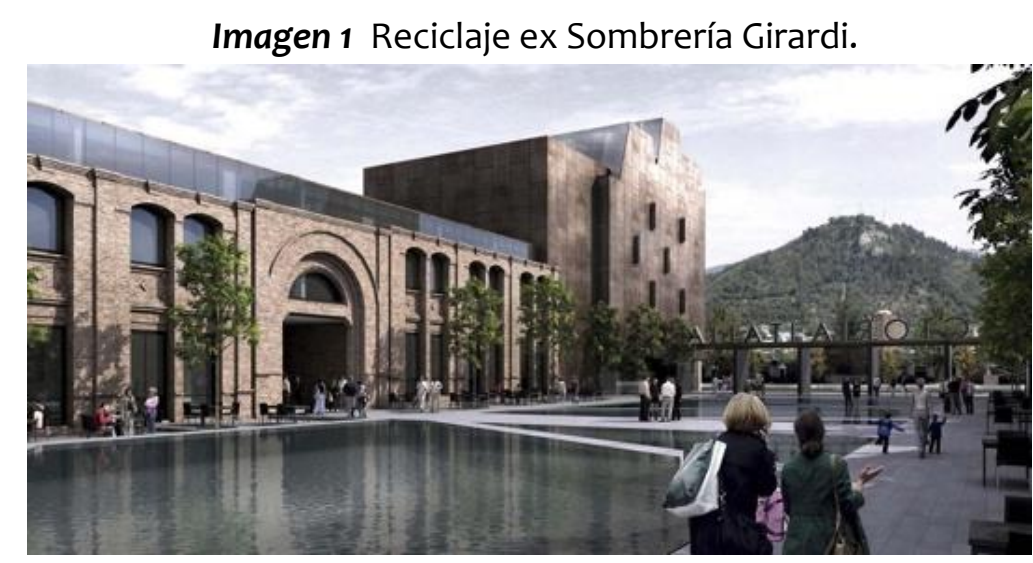

Fuente: Tidy arquitectos, S. López e Ignacio Volante. 
Imagen 2 Reciclaje ex Fábrica Textil Yarur.
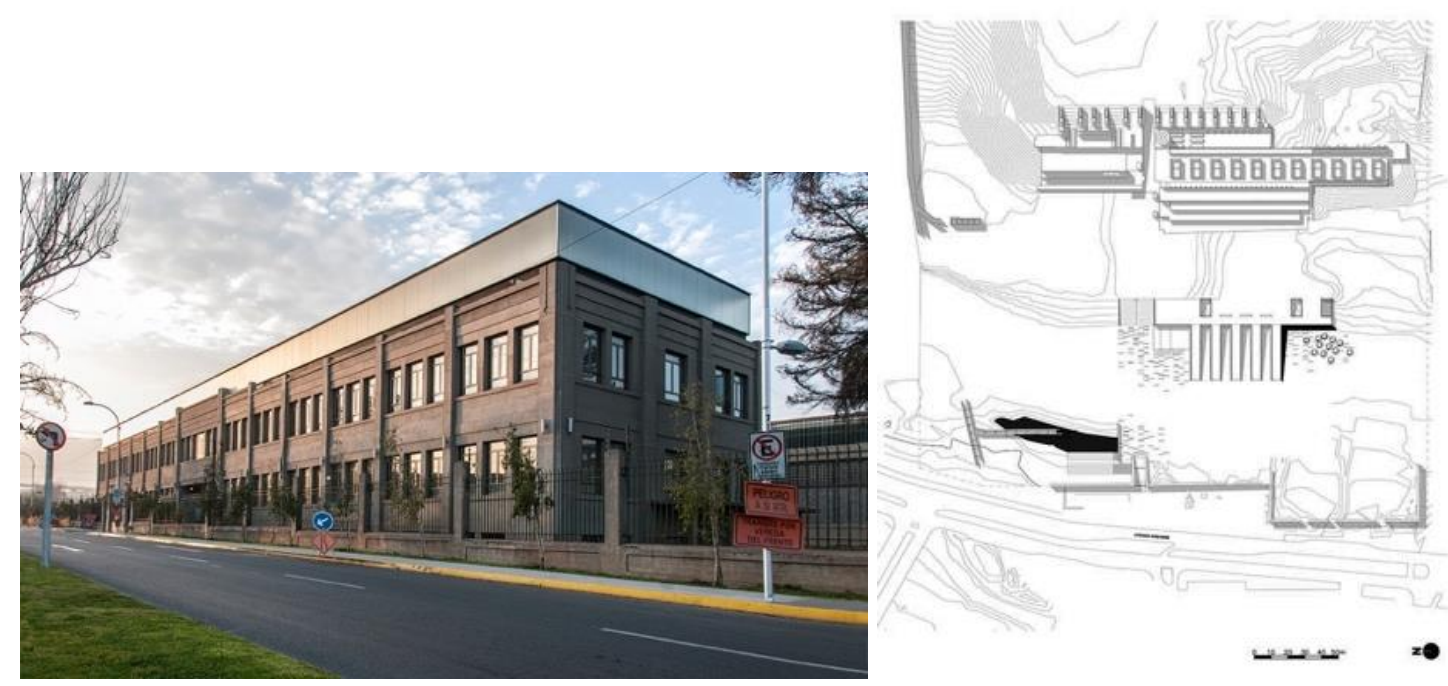

Fuente: Tidy arquitectos, S. López e Ignacio Volante.

Entre los documentos internacionales vinculados al tratamiento del patrimonio industrial que aportan al proceso de reconocimiento y protección del legado cultural industrial destacan, la Carta de Venecia (1964) y luego a un nivel específico la Carta de Nizhny Tagil, la cual lo define como "restos de la cultura industrial que poseen un valor histórico, tecnológico, social, arquitectónico o científico", se trata de "edificios y maquinarias, talleres, molinos y fábricas, minas y sitios para procesar y refinar, almacenes y depósitos" (Carta de Nizhny Tagil, 2003). Luego, en el documento Principios de Dublín (2011), se le otorga importancia a la documentación y comprensión de estructuras, sitios, áreas y paisajes del patrimonio industrial, promueve asegurar una eficaz protección, conservación y mantención de las mismas y finalmente, promueve la difusión de sus distintas dimensiones y valores patrimoniales.

Debido a la extensión de las infraestructuras vinculadas a la producción, magnitud de los espacios y robustez de sus estructuras, el patrimonio industrial permite albergar usos de gran diversidad, como grandes bibliotecas, ferias, centros culturales y expositivos. Destacan a nivel internacional, el Centro Cultural Matadero Madrid, sedes de la CaixaForum en Madrid y Barcelona, el Tate Modern art gallery y Roundhouse en Londres, entre muchos otros. 
Imágenes 3, 4 y 5. Sedes de la CaixaForum en Madrid y Barcelona y Centro Cultural Matadero Madrid.
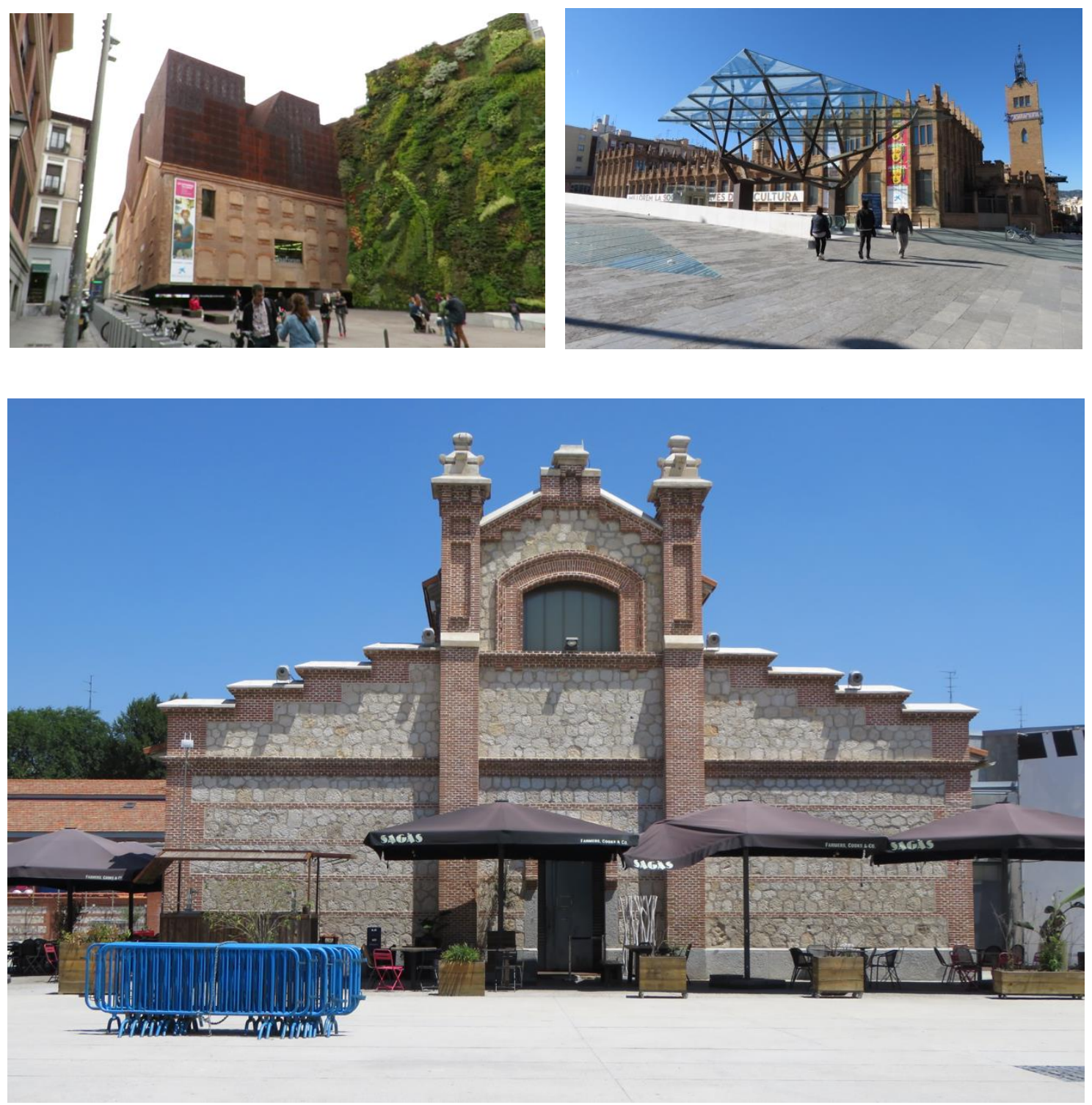

Fuente: Autor.

En el mes de septiembre del año 2018 se desarrolló en Chile el XVII Congreso TICCIH sobre patrimonio industrial Entendiendo el pasado, haciendo el futuro sostenible. Este evento, que convocó a innumerables profesionales vinculados a la recuperación y puesta en valor del patrimonio, pone de manifiesto la vigencia de las ideas sobre intervención sostenible del patrimonio industrial. La Carta UNESCO / UIA de la formación en arquitectura, aprobada en Tokio en el año 2011, considera que "la arquitectura, la calidad de las construcciones y su inserción armoniosa en el entorno natural y construido, así como el patrimonio cultural, tanto individual como colectivo, son cuestiones de interés público", siendo ámbitos que deben ser considerados por los educadores para preparar nuevos arquitectos. Tanto por el interés de las 
comunidades por la protección y cuidado del patrimonio cultural como también, el desafío que significa para los futuros arquitectos las operaciones de ampliación y reciclaje de edificios patrimoniales en base a obras de arquitectura contemporánea, es que los cursos de formación de pregrado en torno a esta temática se consideran relevantes.

El Taller de arquitectura sobre Intervención sostenible del patrimonio cultural, se desarrolla desde el año 2016 en los niveles de formación entre V y VII semestre de la Carrera de Arquitectura en la Universidad UNIACC en Santiago de Chile, abordando a lo largo del curso, la generación de anteproyectos de arquitectura para la recuperación de distintos inmuebles en la ciudad de Santiago, como como las bodegas de Chucre Manzur, el sector urbano de las calles Ruiz de Gamboa con Fernando Manterola en Providencia, los teatros Viel y Novedades, el Teatro de San Bernardo, Taller de Herrería de la Maestranza San Bernardo y el Gimnasio Ferroviario en la misma comuna. Si bien diversos inmuebles de la Región Metropolitana han sido tomados como objeto de estudio, desde 2016 el foco principal del Taller se ha centrado en edificios industriales del sector sur poniente de Santiago, barrio Obrero y Ferroviario San Eugenio.

Imágenes 6 y 7. Proyecto académico para las bodegas de Chucre Manzur, comuna de Providencia.

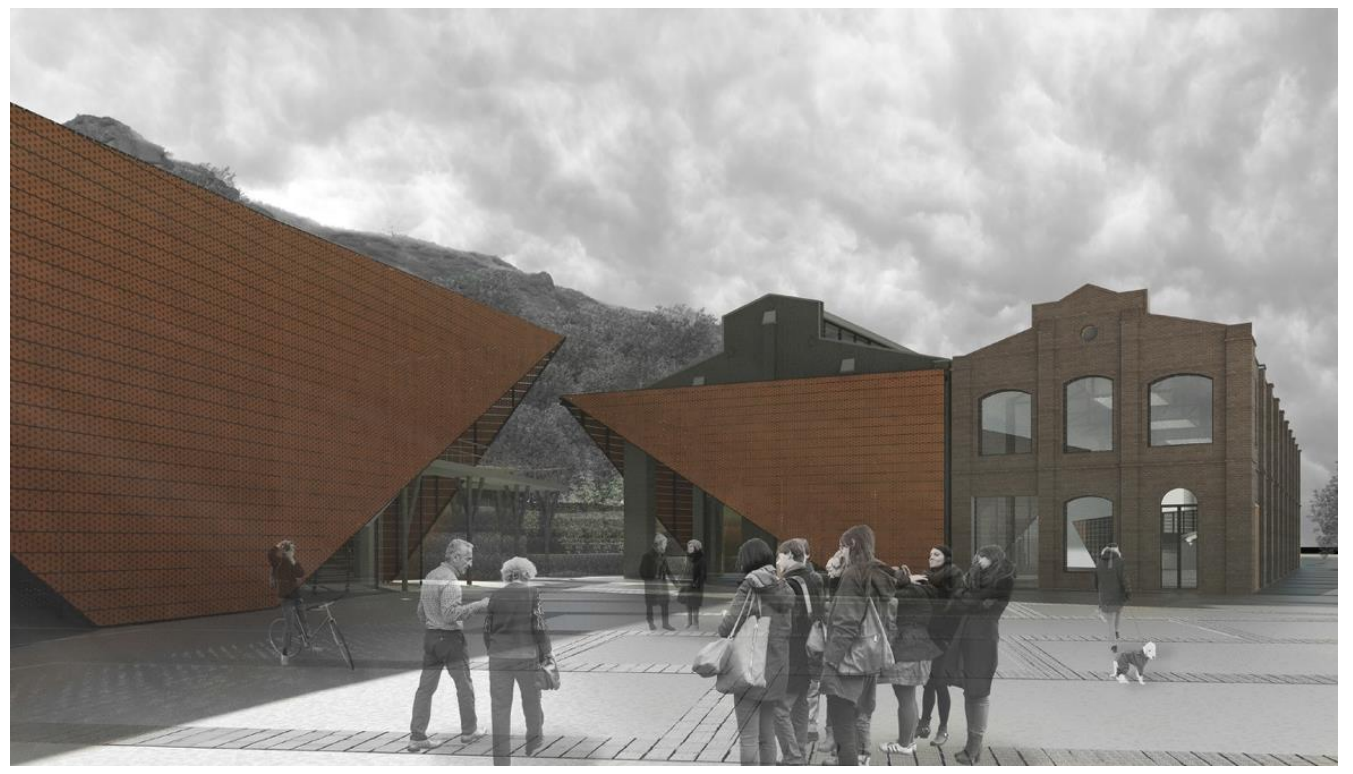

Fuente: Paz Leal. 


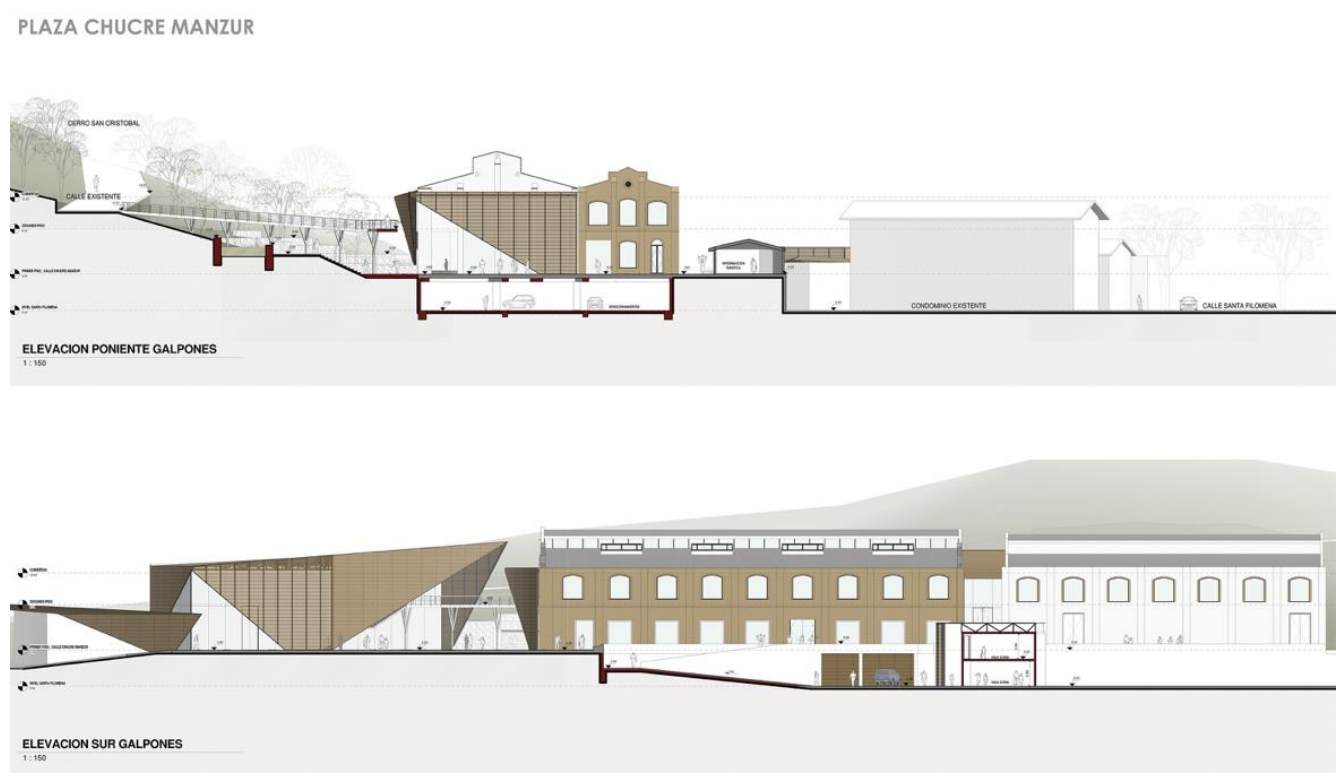

Fuente: Paz Leal.

\section{La identificación del patrimonio del barrio Obrero y Ferroviario como proceso dinámico.}

El barrio obrero y ferroviario San Eugenio se ubica en la zona sur poniente de Santiago de Chile, se trata de un sector de la ciudad que comienza a urbanizarse en la primera década del Siglo XX, tras la construcción de la Maestranza de Ferrocarriles San Eugenio. El barrio hoy cuenta con protección patrimonial local como zona de conservación histórica $(\mathrm{CH})$ y con algunos inmuebles de conservación histórica (ICH) (Ley de urbanismo y construcciones), con respecto a una protección nacional, cuenta con Monumentos históricos (MH) y una Zona típica (ZT) (Ley 17.288).

Numerosas investigaciones han identificado y catalogado el patrimonio del barrio San Eugenio, destacando Pizzi (2010), en El Patrimonio Arquitectónico Industrial en Torno al Ex Ferrocarril de Circunvalación de Santiago. Testimonio del desarrollo industrial manufacturero en el siglo XX, la Tesis de Rodolfo Arriagada; Los atributos patrimoniales del barrio obrero surponiente como catalizadores en sus procesos de reconversión postindustrial (2011), el estudio Memoria explicativa estudio modificación al PRC sector 6 Club Hípico- Parque O'Higgins (2010), y Entre rieles y chimeneas, un recorrido por el barrio Obrero y Ferroviario San Eugenio (2015), entre otros, que ponen de manifiesto el valor de inmuebles específicos ya sea para fundamentar su protección, promoción turística cultural y uso social.

El proceso de reconocimiento de las edificaciones del territorio ha permitido a lo largo de los años identificar nuevos edificios que poseen un atractivo singular desde un punto de vista arquitectónico, social, urbano o económico, en este proceso han 
participado organismos públicos, organizaciones, la comunidad local y la comunidad académica que recurrentemente considera a este territorio como objeto de estudio. De esta manera, a través del Taller de patrimonio, ha sido posible profundizar en la investigación de nuevos hitos como el Sindicato de Molineros San Cristóbal, el Cine Septiembre, Sede de la Corporación Mutual Santiago Watt, Bodegas de la calle Rondizzonni y la Subestación Eléctrica El Mirador.

Imágenes 8 a 16 y 17 a 22. Proyecto académico para la Subestación Eléctrica San Cristóbal, comuna de Recoleta. Reconocimiento del inmueble e imágenes de la propuesta.
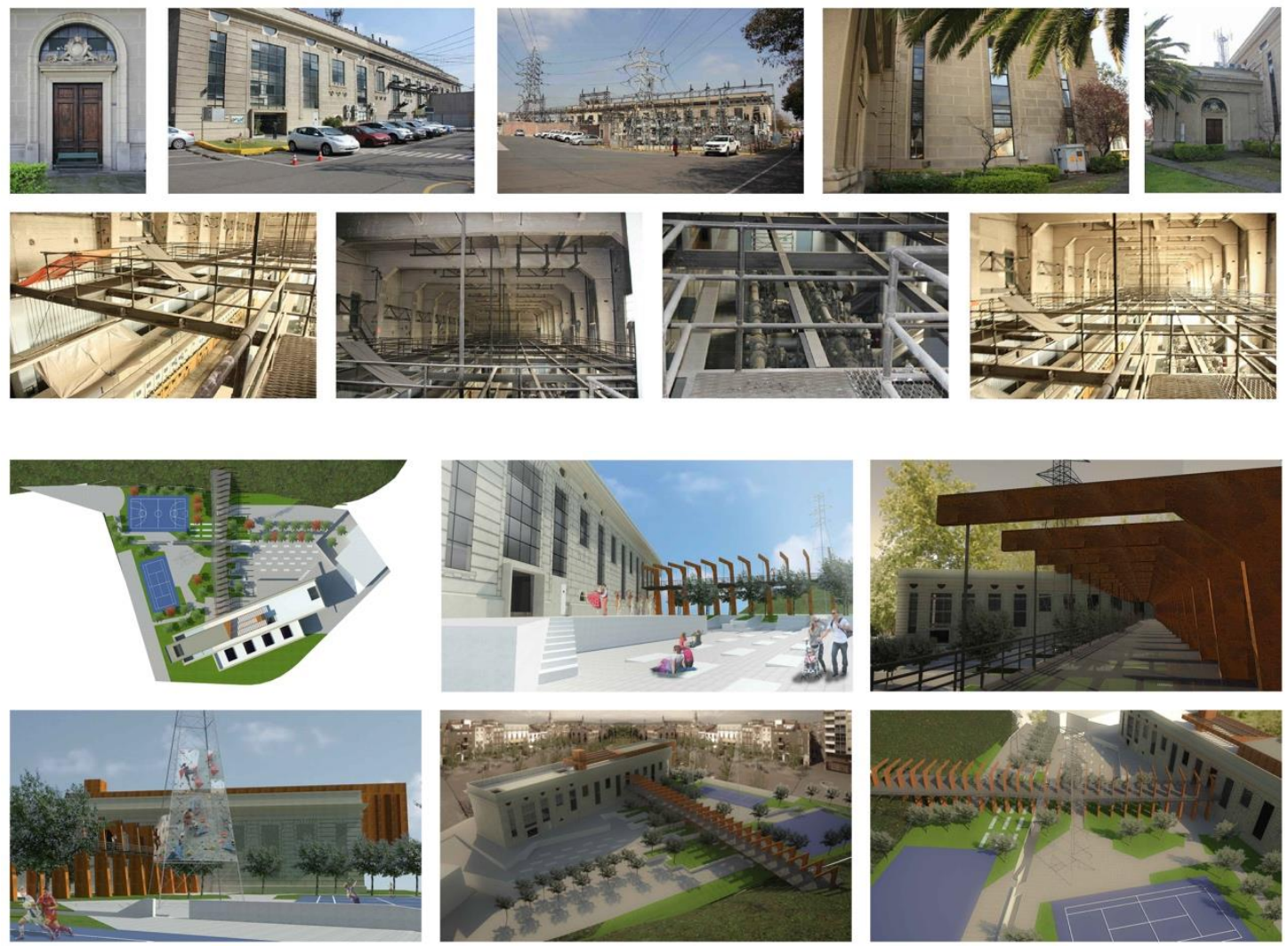

Fuente: José Miguel Aguirre (2017).

Con el paso de los años y como parte del desarrollo natural del sector, edificios representativos del pasado obrero del barrio San Eugenio han sido demolidos y modificados para albergar nuevos usos. Destaca el reciclaje de la ex fábrica Textil Yarur - Machasa, como un centro de televisión y la ex Fábrica Central de Leche como Liceo Industrial. Dentro de los casos menos felices, cuenta el ex Tintorería Yarur Machasa cuya imagen original moderna - brutalista fue alterada por sus actuales ocupantes, quienes le dieron uso como centro de distribución de una cadena de retail nacional. 


\section{Metodología utilizada para el desarrollo del taller.}

El Taller de Intervención sostenible en el patrimonio tiene como objetivo, introducir a los alumnos en el desarrollo de metodologías para la intervención de inmuebles de carácter patrimonial, desarrollando anteproyectos de arquitectura. En lo específico, busca introducir al estudiante en los conceptos teóricos y estado del arte concerniente al patrimonio cultural y su intervención sostenible; estudio histórico, identificación de valores patrimoniales en edificios históricos, realizar un diagnóstico territorial para definir programas y proyectos que contribuyan a un desarrollo armónico barrial, definición de criterios de intervención que permitan un uso sostenible de los inmuebles patrimoniales estudiados y finalmente, la resolución espacial y planimétrica del programa arquitectónico, propuesta estructural y de lenguaje en consecuencia con las disposiciones del programa entregado por la dirección de la escuela de arquitectura.

Imagen 23 Intervención en Subestación Eléctrica El Mirador.

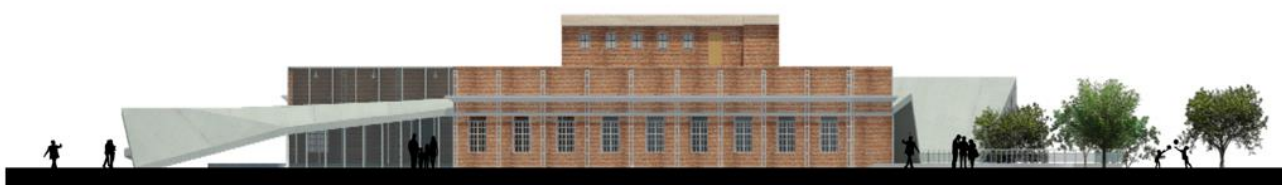

ELEVACION ORIENTE

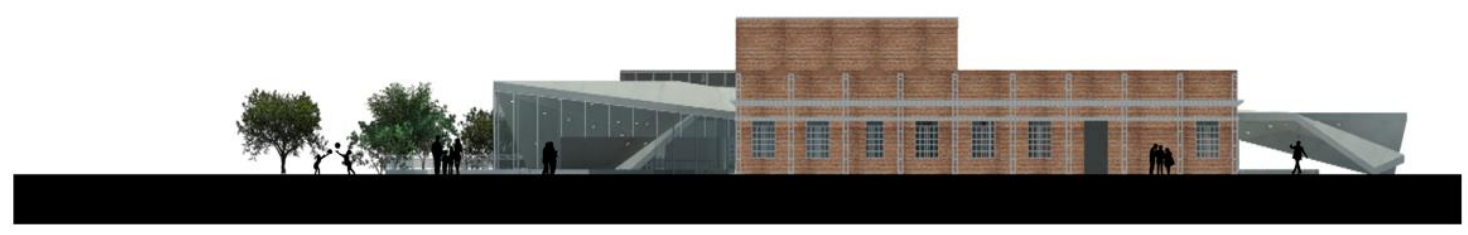

ELEVACION PONIENTE

Fuente: Yuri Mallea y Carla Oyarzún. 


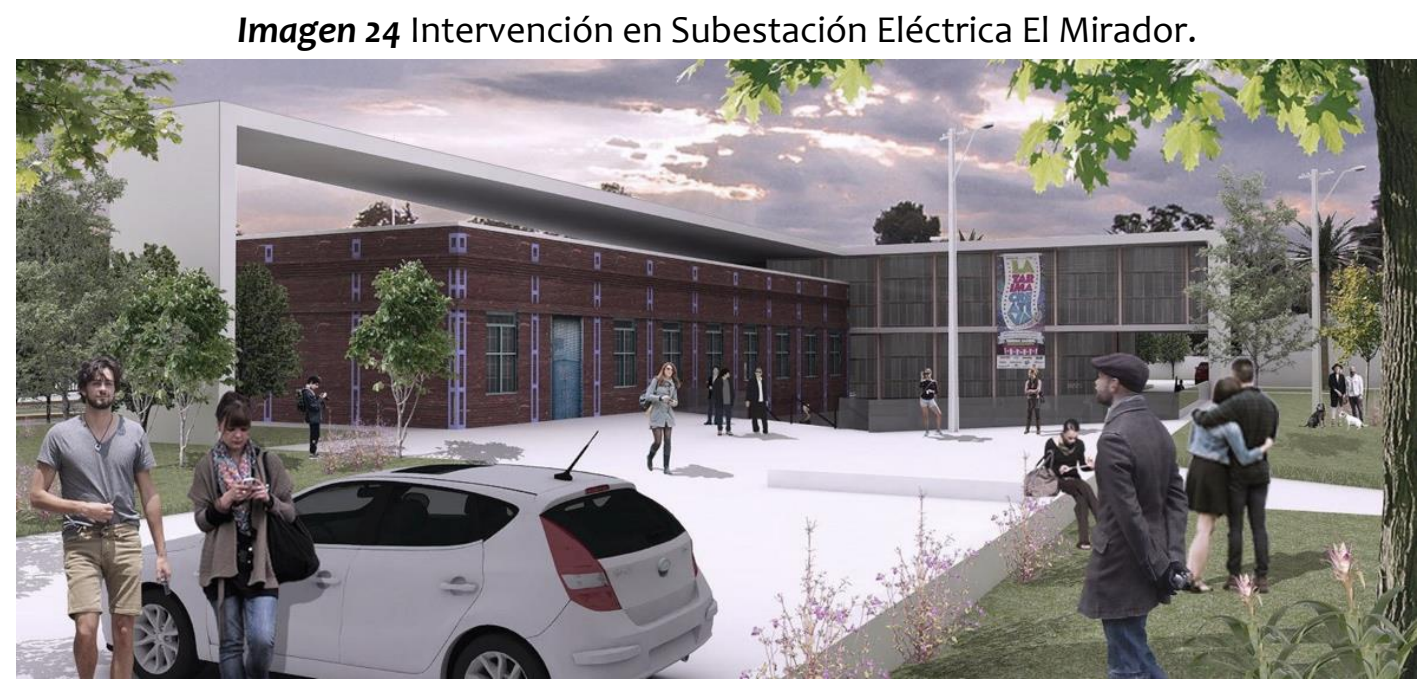

Fuente: Yuri Mallea y Carla Oyarzún.

La metodología implementada en la primera parte del curso, contempla el desarrollo de un análisis que va desde lo general a lo particular, en que cobra valor el estudio urbano-territorial y de los agentes-actores vinculados a cada uno de los inmuebles en estudio. Posteriormente, reduciendo la escala, los alumnos realizan un análisis que contempla el ámbito histórico, planimétrico, usuarios actuales y estado de conservación del edificio para la definición de un proyecto de intervención que tenga como objetivo, reactivar social y económicamente territorios como San Eugenio, que actualmente reciben un menor beneficio por parte de las políticas públicas, así como menor inversión por parte del sector privado.

Dentro de los contenidos teóricos entregados como parte del desarrollo del taller se encuentran, el concepto de patrimonio, principales cartas y acuerdos internacionales, normativa patrimonial de Chile y los principios de intervención del estilo de la Restauración Crítica (Marziano, 2003) como son originalidad, diferenciación, reversibilidad, compatibilidad matérica (o estructural), mínima intervención, entre otros, los cuales son posibles de llevar a intervenciones de arquitectura preexistente en reciclajes y ampliaciones de estos inmuebles, como parte de procesos para su recuperación y puesta en valor.

Un punto central de este proceso, lo constituyen la definición de los valores patrimoniales del edificio en estudio. Estos valores, de orden histórico, urbano, arquitectónico o social, determinan los aspectos principales por los que el inmueble merece ser conservado e intervenido. Así también, estos atributos materiales e inmateriales permiten a los alumnos, plantear criterios de intervención los cuales velen por la conservación de los distintos valores, haciendo sostenible la intervención. 
Finalmente, conviene indicar que en lo actitudinal, este ejercicio busca resaltar la importancia del rol del arquitecto en la sociedad, concientizando a los futuros profesionales sobre la necesidad de cuidado y puesta en valor de estos edificios patrimoniales que son parte de la historia de grupos específicos de la sociedad. Paralelamente, el curso considera las disposiciones del programa entregado por la dirección de la escuela de arquitectura UNIACC. El cierre del Taller se lleva a cabo mediante la exposición de las propuestas ante profesionales invitados, vinculados al patrimonio cultural y externos a la universidad, la que se presenta como instancia de mejora en sus capacidades de construcción y comunicación del discurso arquitectónico.

Imágenes 25 y 26. Modelos finales, alumnos Carla Oyarzún y German Soto.
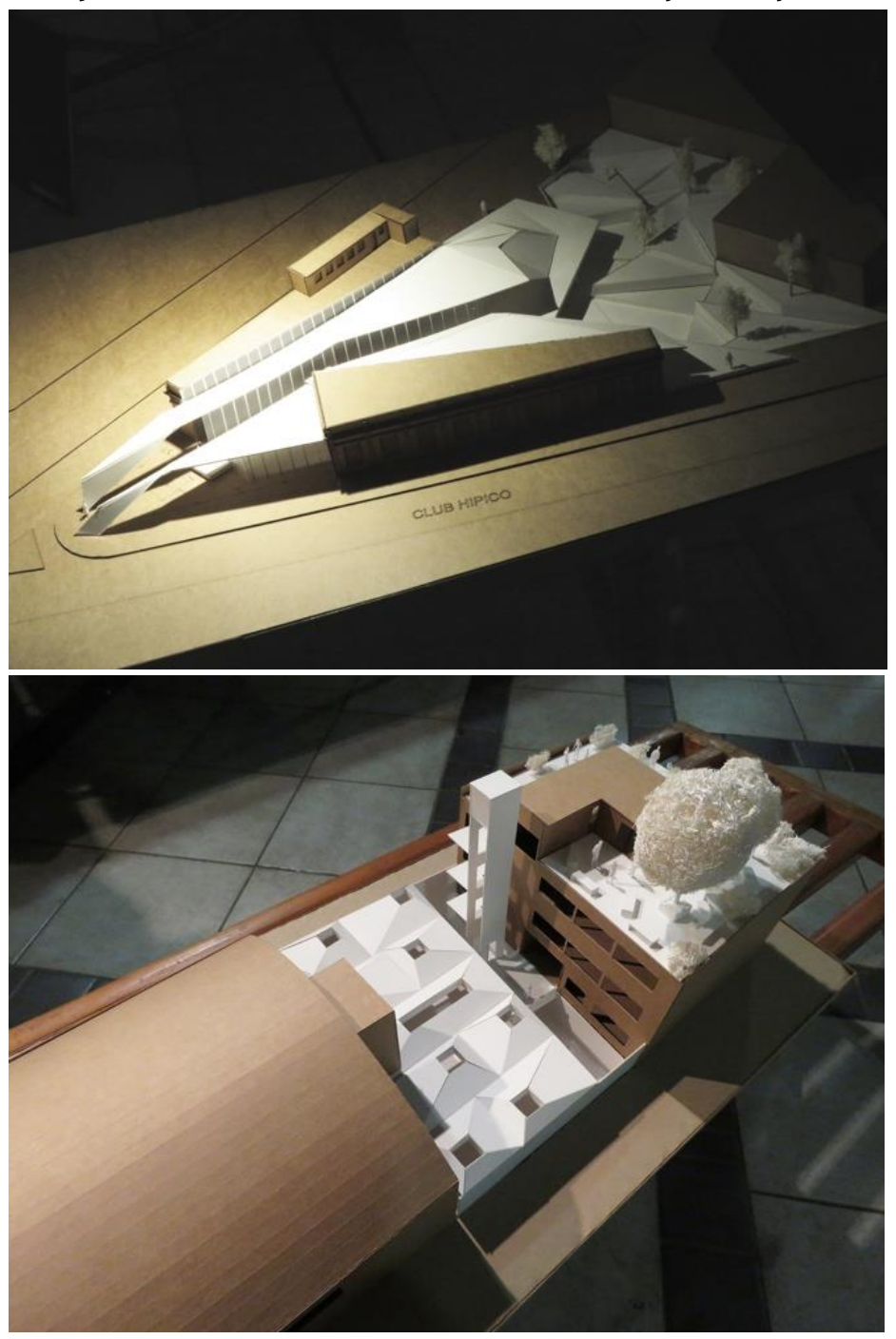

Fotografías del autor. 


\section{Referencias}

Arriagada, R. (2011). Los atributos patrimoniales del barrio obrero surponiente como catalizadores en sus procesos de reconversión postindustrial. Tesis para optar al título de Arquitecto y Magíster en Desarrollo Urbano. Escuela de Arquitectura, Diseño y Estudios Urbanos de la Pontificia Universidad Católica de Chile.

Carta de Venecia (1964). Carta Internacional sobre la Conservación y la Restauración de Monumentos y Sitios. In II Congreso Internacional de Arquitectos y Técnicos de Monumentos Históricos.

Consejo Internacional de Monumentos y Sitios \& Comité Internacional para la Conservación del Patrimonio Industrial (2011). The Dublin Principles, Joint ICOMOSTICCIH Principles for the Conservation of Industrial Heritage Sites, Structures, Areas and Landscapes (XVII ICOMOS General Assembly, 28-Nov-2011). Recuperado de http://ticcih.org/about/about-ticcih/dublin-principles/

Gobierno de Chile (2012). Hacia una nueva política urbana en Chile. Documento borrador 27-11-2012. Recuperado el 20 de diciembre de: http://politicaurbana.minvu.cl/wpcontent/uploads/2012/11/Borrador_PNUD_27112 012.pdf

International Union of Architects, UNESCO (2011). Carta Unesco/UIA de la formación en arquitectura. Versión revisada 2011. Aprobada por la Asamblea General de la UIA, Tokio.

Ley $\mathrm{N}^{\circ} 17.288$ (4 de febrero de 1970). Ley de Monumentos Nacionales y Normas Relacionadas.

Ley $\mathrm{N}^{\circ} 20.703$ (13 de abril de 1976). Ley y Ordenanza General de Urbanismo y Construcciones.

Marziano, S. (2003). La cuarta dimensión en arquitectura. Teoría e historia de la restauración. Santiago: Arqvitempo.

Municipalidad de Santiago (2010). Memoria explicativa estudio modificación al PRC sector 6 Club Hípico-Parque O`Higgins. Recuperado de http://seia.sea.gob.cl/archivos/memoria_explicativa_CH_noviembre.pdf

Pizzi, M., Valenzuela, B., Paz, M. \& Benavides, J. (2010). El Patrimonio Arquitectónico Industrial en Torno al Ex Ferrocarril de Circunvalación de Santiago. Testimonio del desarrollo industrial manufacturero en el siglo XX. Santiago: Editorial Universitaria. 
Tagiol, N. (2003). La Carta de Nizhny Tagil para el Patrimonio Industrial. Internacional Commitiee For The Conservation Of The Industrial Heritage.

\section{Luis Rojas Morales}

Magister en Desarrollo Urbano IEUT UC. Arquitecto Universidad Central. Diplomado en Patrimonio Cultural y en Gerencia Pública. Fundador Colectivo Rescata y Docente de la Escuela de Arquitectura UNIACC. 